\section{Intersections}

Canadian Journal of Music

Revue canadienne de musique
Intersections CANADIAN JOURAL OR MUSIC

\title{
Experiencing Time in Brian Cherney's String Quartet No. 4 (1994)
}

\section{Christoph Neidhöfer}

Volume 37, numéro 1, 2017

Illuminations: Essays in Honour of Brian Cherney

URI : https://id.erudit.org/iderudit/1059891ar

DOI : https://doi.org/10.7202/1059891ar

Aller au sommaire du numéro

\section{Éditeur(s)}

Canadian University Music Society / Société de musique des universités canadiennes

ISSN

1911-0146 (imprimé)

1918-512X (numérique)

Découvrir la revue

Citer cet article

Neidhöfer, C. (2017). Experiencing Time in Brian Cherney's String Quartet No. 4 (1994). Intersections, 37(1), 119-142. https://doi.org/10.7202/1059891ar
Résumé de l'article

Dans un mouvement d'une durée d'une demi-heure, le Fourth String Quartet (1994) de Brian Cherney est frappant par sa cohérence formelle et la diversite du matériel. L’oeuvre atteint une vaste cohésion non seulement par le jeu complexe de trois « structures principales » qui se manifestent simultanément—quatre mouvements attacca en un, à un niveau, sept sections formant certaines proportions temporelles à un autre, et quatre cycles de " rythmes de respiration » dérivés des mêmes proportions à un troisième niveau, comme le révèlent les sources du manuscrit-mais aussi par la tension fluctuant continuellement que nous sentons dans tout le mouvement entre le temps ontologique et le temps psychologique. L'auteur fait appel à la notion de Pierre Souvtchinsky de « contrepoint » entre le « temps ontologique » (c.-à-d. le temps réel, celui de l'horloge) et le temps propre à une oeuvre musicale, façonné par les " moyens matériels et techniques » employés pour exprimer la musique pour montrer comment, dans le quatuor de Cherney, les proportions fixes et les polyrythmes lents et stables à l'arrière-plan créent un espace où peut se dérouler l'activité à l'avant-plan qui a son propre sens du temps. L'auteur explore aussi la notion de temps dans une dimension métaphorique secondaire touchant diverses allusions intertextuelles dans le quatuor.
Copyright @ C Canadian University Music Society / Société de musique des universités canadiennes, 2019
Ce document est protégé par la loi sur le droit d'auteur. L’utilisation des services d'Érudit (y compris la reproduction) est assujettie à sa politique d'utilisation que vous pouvez consulter en ligne.

https://apropos.erudit.org/fr/usagers/politique-dutilisation/ 


\title{
EXPERIENCING TIME IN BRIAN CHERNEY'S STRING QUARTET NO. $4(1994)^{1}$
}

\author{
Christoph Neidhöfer
}

My first encounter with the Fourth String Quartet of Brian Cherney (b. 1942) was during a live performance I attended by the Lloyd Carr-Harris String Quartet over a decade ago. I vividly remember the focused tension and coherence of the intricate sound world that captivated me throughout the half-hour of the work's duration. Time in an external, physical sense seemed often to have been suspended, and I felt as though I were being drawn into a rich labyrinth of different internal temporal spaces. I found the long stretches of very quiet music somewhere around the middle of the work to be particularly striking. Even though at this point the music was replete with rests, repeatedly "stopping," it somehow maintained its flow and tension, which evidently could have materialized only because of the particular way this moment was set up within the trajectory of the work. When the silences then gave way to extended soft multilayered undulating but static pitch pulsations never heard to this extent before in the work, I seemed to be regaining a sense of measurable time. But by this point I could no longer tell whether the music was slow or fast, because this depended on what I chose to hear as my point of reference. In a sense, the music was (moderately) fast and slow at the same time. Once individual gestures began to drift across larger pitch spaces again in a manner familiar from earlier in the movement, abandoning the sustained static layers, I recuperated a clearer sense of tempo. When eventually widely spaced harmonic textures from earlier in the piece returned, I began to feel that the music could go on forever. And I still felt this way when the movement came to a close. The work

1 I would like to thank Brian Cherney for generously sharing with me the sketch materials and unpublished score of his Fourth String Quartet, for the numerous conversations we have had about this work and his music more broadly, and for his feedback on an earlier draft of this article. In a number of instances, the composer was my direct source of information, as acknowledged in each case. Excerpts from the score and other source materials for String Quartet no. 4 are reproduced here with the kind permission of the composer. I would also like to thank participants at the symposium "Illuminations: Brian Cherney at 75" (McGill University, 27-8 October 2017) for their questions and comments on the conference paper from which this article developed, as well as the two anonymous peer reviewers of the article manuscript for their feedback and suggestions. Furthermore, I wish to thank Danniel Ribeiro for his expert setting of musical figures 1, 3, 5, 7, 18, 19, and 20 in computer software. Preparation of this article was supported by a grant from the Social Sciences and Humanities Research Council of Canada. 
both ended with, and continued into, the silence that followed the final harmonics. How did this all come about?

In what follows I would like to answer this question by examining how in Cherney's Quartet time is structured and how we experience it, through an analysis of the score, the composer's sketches, and the listening process. Let us begin with three passages from early in the work. Figure 1 shows the opening four bars of the score. ${ }^{2}$ Very soft sustained or pulsating harmonics are enveloped in oscillating, slowly rising and falling flautando gestures. The sustained opening dyad in the cello is static. When the second violin enters three quarters later, it colours that dyad by quickly moving back and forth between its two pitches $\mathrm{A}_{5}$ and $\mathrm{F}_{\sharp 5}$ and then rising above to a harmonic E6 (bar 2), which after a rest is held and repeated together with a harmonic D6. In bar 1 the viola, shadowing the cello and second violin, doubles the $\mathrm{A}_{5}$ (as harmonic) around the time when the second violin comes in and from it picks up G5 (also as harmonic) at the end of the bar. The slowly ascending music in the second violin is followed, starting in the second half of the second bar and intensified in the third bar, by overall mostly descending wavy and tremolo lines in the upper three strings, fading out on the second beat of the fourth bar, and leaving behind static harmonics. I would argue that in the absence of any audible metric pulse-the listener can discern neither the notated $6 / 4$ metre in $\bullet=60$ nor any other consistent regular pulse-tempo is experienced here in terms of the varying densities by which the material unfolds. Borrowing terminology coined by Karlheinz Stockhausen, we can say that at the very beginning and at the very end of this passage, time passes more slowly than in between, because the excerpt starts with and returns to a low density of change of events (Veränderungsdichte). ${ }^{3}$ With the entrance of the second violin in bar 1 , there is more information to process in time-first the oscillation between $\mathrm{A}_{5}$ and $\mathrm{F}_{55}$, then upward expansion of the pitch material into bar 2 with similar rhythms but a slight crescendo, followed by a sudden rest and (perhaps unexpected) high double stop of harmonics, etc.- -and hence, as Stockhausen would assert in such a situation, time passes more quickly here.

Figure 2 illustrates the fluctuating density and rate of change as we may experience them over these four bars, showing clock time on the $x$ axis and the perceived amount of change on the $y$ axis. The representation here is approximate and intuitive, rather than applying any strict metrics, and not intended to reflect every fine detail. The graph line running from left to right symbolizes the overall effect of three components: first, the line tracks the degree of change over time (Veränderungsgrad in Stockhausen's terminology, i.e., the sharper the change, the steeper the curve will be at a particular point); second, the relative height of the line reflects the rate (speed) by which change occurs (density of change, Veränderungsdichte); and third, the graph takes into account the fact-well known to composers-that a constant degree or rate

2 The added vertical arrows (as those in figures 3, 5, 7, 18, and 20 below) are for later discussion.

3 Stockhausen introduces the term Veränderungsdichte (density of change) in Stockhausen ([1955] 1988). 


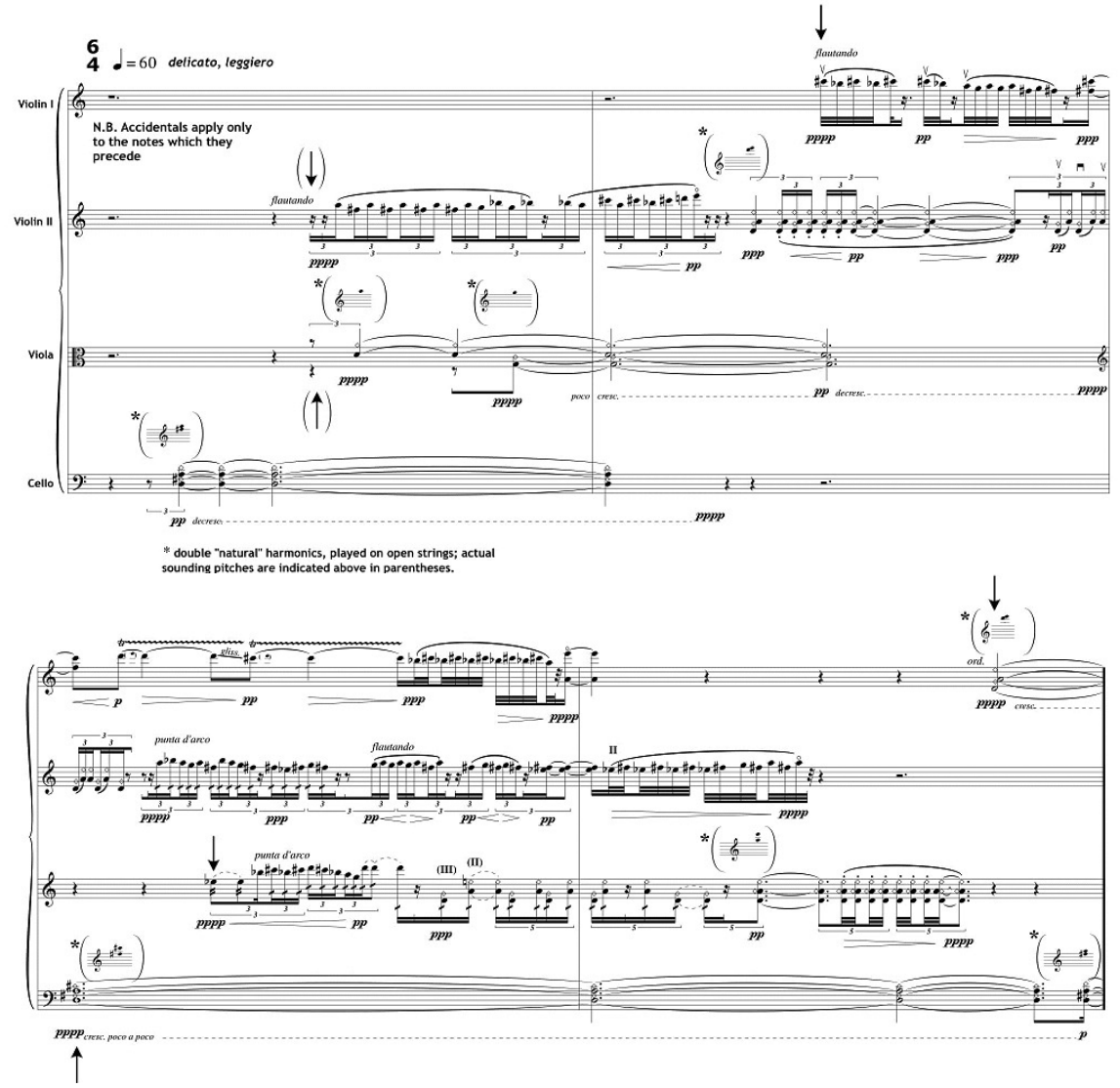

Figure 1. Brian Cherney, String Quartet no. 4, bars 1-4, vertical arrows added

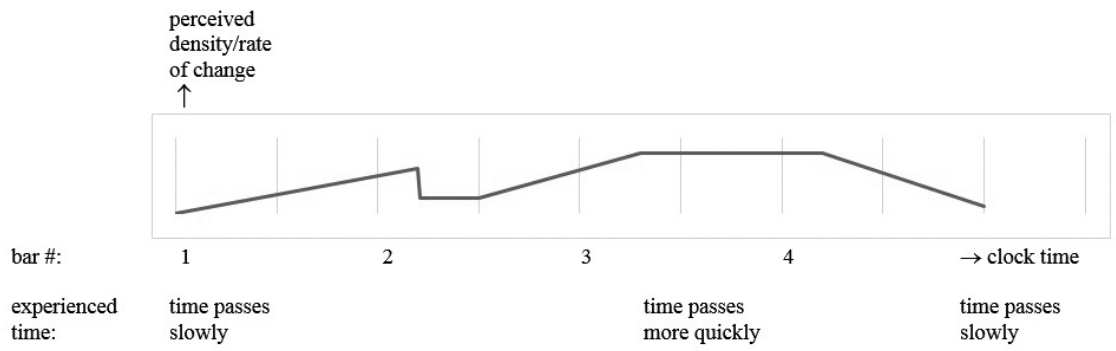

Figure 2. Perceived density and rate of change in bars 1-4

of change will actually be perceived by the listener as a gradual drop in the intensity of change. In such a case, as, for example, in bar 4 of the graph, the curve gradually descends, even though the rate and degree of change are about constant (compare with figure 1, bar 4). By the same token, to maintain an approximately even level of perceived density and rate of change, there needs to be an increase in change in some component(s). This I would argue is the 
case in bar 3 (figure 1), where subtly intensifying activities-trills and a larger number of runs-provide a continuously and modestly increasing level of new stimuli over time, for which reason I keep the curve in figure 2 mostly in a horizontal position for that bar. In other words, one component can weaken or strengthen the effect of another. With respect to the listening experience, the changing height of the curve in figure 2 now shows where time appears to pass more slowly and where it goes by more quickly, as I have noted at the bottom of the figure.

The beginning of the excerpt shown in figure 3 contains some of the quietest and most static music found in the quartet. (This kind of texture shines through in many other parts of the work and occurs again for a more extended stretch of time towards the end in bars 387-400.) While there is again no audible metric pulse, the double stops in first violin, viola, and cello each "breathe" at a constant rate: five quarters of sustained double stop followed by a quarter rest repeated in the cello, eight quarters of double stop followed by a rest of two quarters repeated in the viola, and ten plus three quarters twice in a row in the first violin. The overall effect of these superimposed repeated durations articulating a stationary pitch field is one of evenly passing time, or perhaps gradually more slowly passing time. When faster runs return with increasing intensity in bars 40-2, time appears to pass more quickly again (because we have more information to process in time), then more slowly in bars 43-4, and suddenly much more quickly at the end of bar 44 (until bar 46 , not shown), as illustrated in figure 4.

In the third through fifth bar of the passage shown in figure 5 (bars 81-3) time passes evenly because we hear a regular pulse in the cello (pizzicato) set against stationary pitches (arco) with only slight expressive development, i.e., only small changes in dynamics (crescendo in first violin and viola, decrescendo in cello in bar 83) and register (meandering contour in cello), which keep the perceived density and rate of change at about a constant level. This is shown in figure 6 by the horizontal line for bars 81-3. In bar 84 (figure 5) the density of information increases (subtle but sudden parallel minor-sixth motion in viola and cello, shifting double stops in first violin), with the perceived rate of change then continuously slowing down over the next bars. This is shown in figure 6 by the descending line for bars $84-8$. The rate and density of change of information in the first two bars (figure 5, bars 79-80) is quite high, on the other hand, and probably perceived as increasing, for which reason I show an elevated ascending line for these two bars in the graph of figure 6. This is one of the many places in the work where Cherney transitions from one tempo to another via metric modulation, as he indicates in the score below the second violin part of bars 79-80 (figure 5): in bar 80 the audible pulse unit in the second violin of five sextuplet sixteenths in tempo $\bullet=90$ equals the following quarter pulse in tempo $\bullet=108$ heard in the cello.

It is in places such as this (bars 80-3) that the music imparts a sense of clock time, evoked by an audible regular pulse, here at tempo $\bullet=108$. From bar 84 on listeners will probably retain this sense of clock time for a little while longer, even though soon the regular quarter beat is no longer articulated. We 

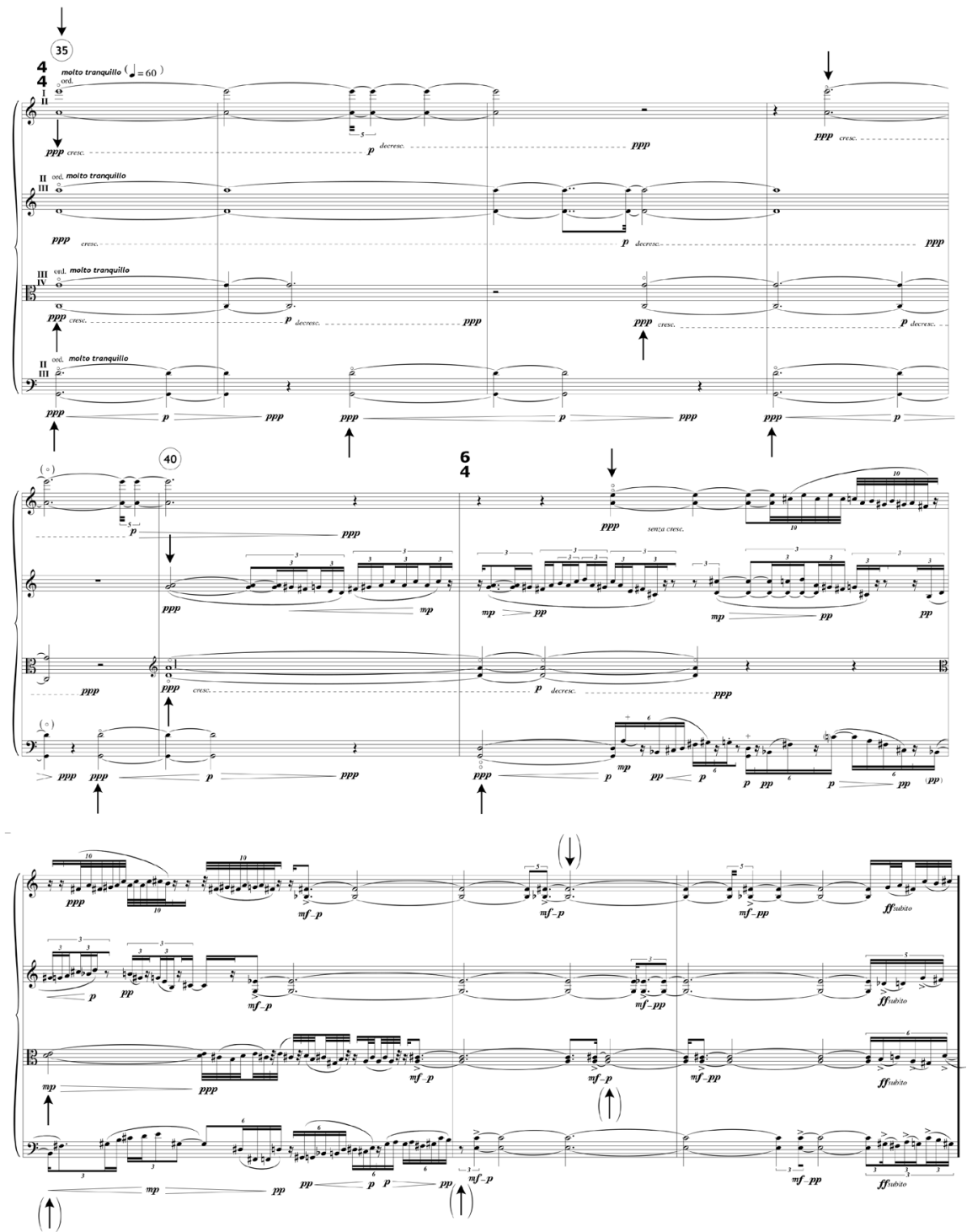

Figure 3. Bars 35-44, vertical arrows added

probably feel that from bar 85 on the musical events start to rub against the regular beat of clock time, that is, that the sixths sounded in the viola and cello appear somewhat out of sync with the pulses of clock time, with these sixths entering mostly somewhat before or after these implied pulses. In other words, bars 84-7 are a composed-out rubato; if we were not looking at the score we would probably think that the performers were freely slowing down and speeding up in the manner of espressivo playing. Such a composed-out rubato 


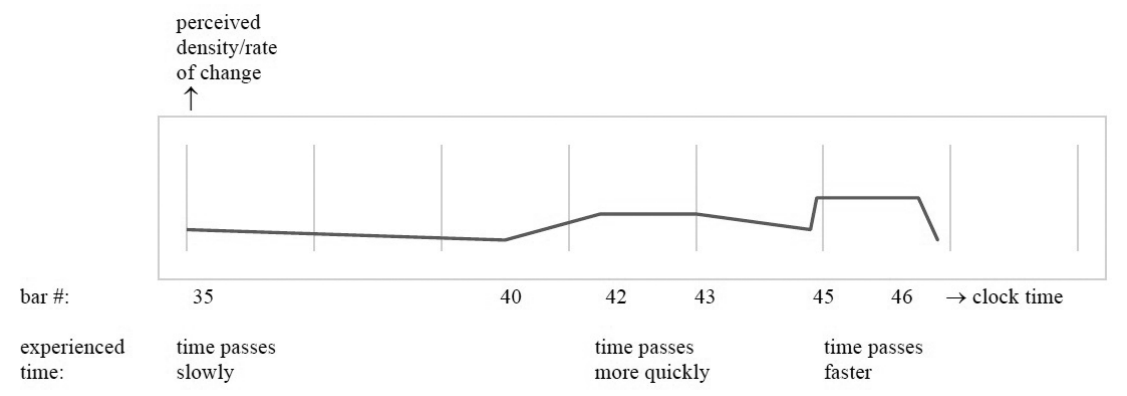

Figure 4. Perceived density and rate of change in bars $35-46$
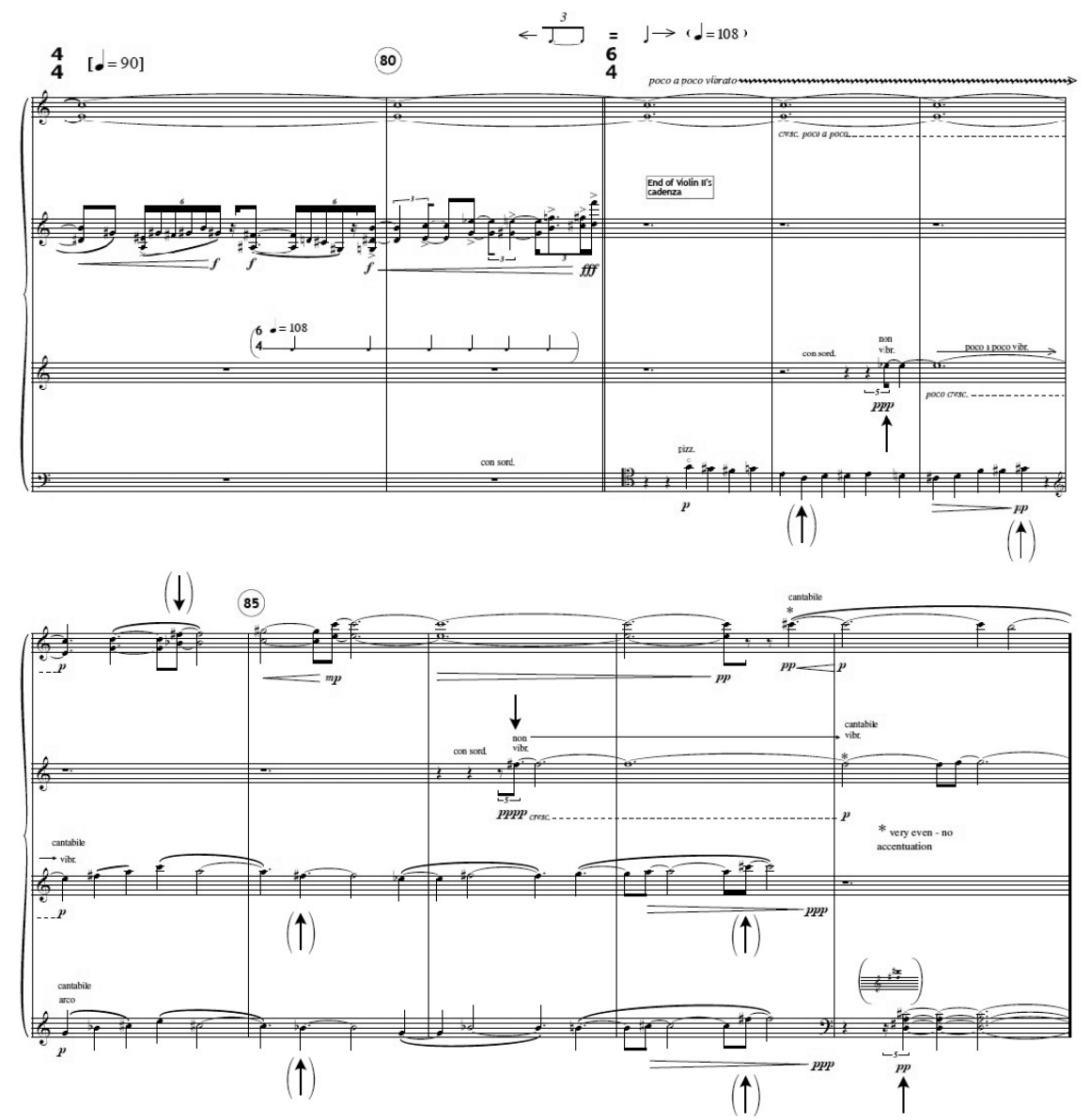

Figure 5. Bars 79-88, vertical arrows added. The passage features metric modulation from tempo $\bullet=90$ to tempo $\bullet=108$ in bars $80-1$. 


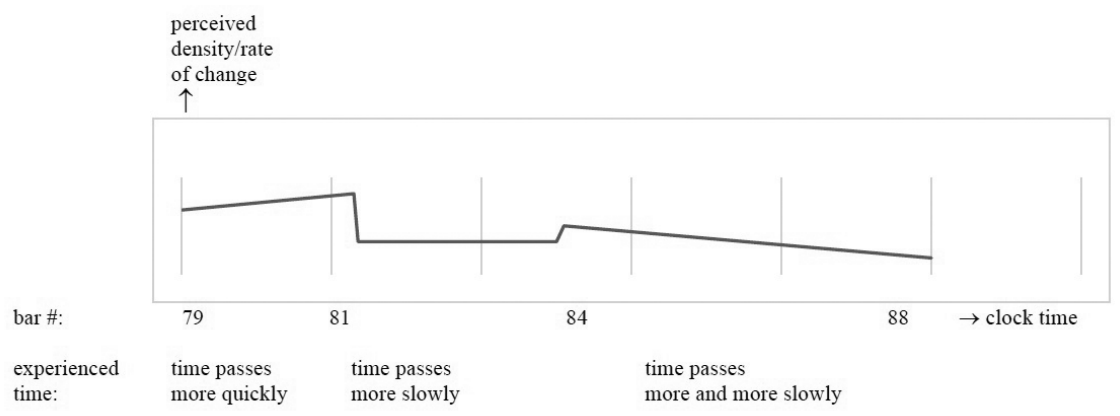

Figure 6. Perceived density and rate of change in bars 79-88

is reminiscent of the music of Elliott Carter, as are the metric modulations and certain other features in the quartet to be discussed later on. ${ }^{4}$

The play in this excerpt with moving into and out of clock time, where the heightened expression in bars 84-7 detaches us from clock time as experienced in the preceding bars, reminds me of the distinction Pierre Souvtchinsky (1939) drew between music paralleling ontological time and music associated with psychological time:

In music there is a peculiar relationship, a kind of counterpoint, between the unfolding of time, its real duration, and the material and technical means by which this music is expressed and notated.

The musical material either adequately carries out this [real] course of time, which so to speak "leads" the music and determines its temporal form, or else the musical material abandons this flow of time, shortening it, widening it, or convulsively transforming its normal course.

Music of the first kind can be called chronometric, music of the second kind chrono-ametric.

In chronometric music the sense of time is in balance with the musical process; in other words, ontological time unfolds completely and uniformly in musical time. At its primary creative basis chronometric music is characterized by the absence of emotional and psychological reflexes, which allows it to seize the course of ontological time and to penetrate it ....

By its very nature, chrono-ametric music is always psychological; only this kind of music can express psychological reflexes .... In principle, in this music centres of attraction and gravity are displaced. They occur neither at the sounding moment nor in what is musically given [implied], but are always shifted ahead or behind (most of the time ahead), thus breaking 
with the normal flow of musical time and destroying the primacy of the "musical moment." This music either overtakes real time or lags behind. 5

After mentioning the music of Bach, Haydn, Mozart, and Verdi as examples of chronometric music, Souvtchinsky goes on to explain that "in modern music it is Igor Stravinsky who has renewed and continued chronometric music."6 As the most typical chrono-ametric music he singles out that of Wagner. A more recent example of this type of music, as Ernst Krenek notes, would be that of Arnold Schoenberg and his school (not mentioned by Souvtchinsky).7 While a critique of the particulars of Souvtchinsky's classification and of his concomitant value judgment lies beyond the topic of this article, I would argue that the basic distinction he proposes can usefully be applied to the analysis of a wide range of music, Cherney's included. ${ }^{8}$ In Souvtchinsky's terms, we can

5 Il y a dans la musique une relation particulière, un genre de contrepoint entre l'écoulement du temps, sa durée propre et les moyens matériels et techniques à l'aide desquels cette musique a été exprimée et notée.

Ou bien la matière musicale remplit de façon adéquate le cours du temps, qui pour ainsi dire 'conduit' la musique et détermine sa forme temporaire, ou bien elle abandonne ce cours du temps, l'abrégeant, l'élargissant ou transformant convulsivement son cours normal.

Dans le premier cas, la musique peut être appelée chronométrique, dans le second chrono-amétrique.

Dans la musique chronométrique le sens du temps est en équilibre avec le processus musical; en d'autres termes, le temps ontologique évolue entièrement et uniformément dans la durée musicale. Dans sa base créatrice primaire la musique chronométrique se caractérise par l'absence de réflexe émotif et psychologique, ce qui lui permet de saisir le processus du temps ontologique et d'y pénétrer ....

La nature de la musique chrono-amétrique est toujours psychologique; ce n'est que par elle que peuvent être exprimés les réflexes psychologiques ....

Dans cette musique, les centres d'attraction et de gravité sont, en somme, déplacés. Ils ne se trouvent point dans l'instant sonore, ni dans la donnée musicale, mais sont toujours placés en avant ou en arrière (en avant pour la plupart du temps) rompant ainsi avec le cours normal du temps musical et détruisant la prédominance de "l'instant musical". Ou bien la musique devance le temps réel, ou bien elle demeure en arrière. (Souvtchinsky 1939, 73; my English translation, emphases in the original)

6 "Dans la musique moderne, c'est Igor Strawinsky qui a été le rénovateur et le continuateur de la musique chronométrique" (Souvtchinsky 1939, 75, my translation). Stravinsky adopts Souvtchinsky's classification in the second of the Charles Eliot Norton Lectures, delivered at Harvard in 1939-4O and published as Poetics of Music (Stravinsky 1942). Stravinsky's lectures were in fact written in collaboration with Souvtchinsky and Roland-Manuel (Soumagnac 2000; Dufour 2004; Akimova 2011, 86-9).

7 Krenek ([1944] 1993, 11).

8 Krenek, for one, agrees with Souvtchinsky's distinction, but not his (and Stravinsky's) value judgment, and has no problem associating his (Krenek's) own music with psychological time (Krenek [1944] 1993, 13). Krenek refers to Souvtchinsky via the second lecture of Stravinsky's Poetics of Music and not Souvtchinsky's original article. Elliott Carter was directly influenced by the ideas on musical time by Souvtchinsky and others (including Koechlin 1926 and Brelet 1949; see Carter [1976] 1997 and [1965/94] 1997). With respect to Souvtchinsky's characterization of "chronometric" and "chrono-ametric" music, Carter notes,

Different composers stress different combinations of "real" and "psychological" time-in Haydn, Mozart, and Stravinsky, the music is what Suvchinsky [sic] calls "chronometric," since the sense of time is equivalent to the musical process of the work. Musical time is 
say that bars $81-3$ of figure 5 evolve parallel to ontological time and thus represent chronometric music, while the following bars $84-8$ are likely associated with psychological time, because they get out of sync with ontological time as pointed out earlier, and thus represent chrono-ametric music. That Cherney's music features both types is noteworthy but, as such, not surprising, given that both the music of Stravinsky and Béla Bartók, on one hand, and that of the Second Viennese School, on the other, have been major influences on Cherney. The pizzicato phrase in the cello of bars 81-3 is in fact one of several allusions to Bartók in this quartet, as we will see. Bars $84-7$ are espressivo in the way Stravinsky's music never is and are more in line with the expressive character of the music of the Second Viennese School.

In the way Souvtchinsky describes chronometric and chrono-ametric music as being in or out of sync respectively with ontological time, his classification presupposes the presence of an audible or intuited metric pulse. But a good deal of music written since the mid-twentieth century does away with an audible metric pulse altogether (including some of Stravinsky's own later serial music from the 1950s and 1960s, such as in passages of Movements from 19589). Cherney's quartet likewise contains much of what I will call audible-metrefree music. ${ }^{9}$ We saw instances of this in figure 1 and in figure 3 after bar 40 (we may or may not perceive a metre in the preceding bars). Figure 7 shows a later passage that is also largely audible-metre-free, except for the metric modulation foregrounded in the viola in bars 233-4, where we briefly do hear a regular pulse (dotted eighth in bar 233 equalling the quarter in bar 234). In bars 230-1 the material flows only tentatively, with frequent stops. The following bars 232-5 are more continuous, with soft sustained double stops familiar from figure 3 shining through. Bars 236-8 (downbeat) then restate the material from the earlier bars 230-2 (downbeat) exactly, except for presenting it in a faster tempo of $\bullet=72$ instead of $\bullet=54$ and reducing the two half rests in bar 230 to quarter rests in bar 236. Cherney presumably wants us to experience the same music the second time without a drop in our attention span, and hence repeats it at a faster pace as per the rationale I mentioned earlier. In a literal repeat at the same speed, time would have been perceived as passing more slowly. In the way Cherney presents it, the repeated passage now has about the same intensity (i.e., perceived density and rate of change) as when we first heard it in the slower tempo. ${ }^{10}$ In the absence of any audible pulse or other salient rhythmic

equivalent to ontological time, while the music of the Romantic composers, particularly that of Wagner, is "chrono-ametric," since it has an unstable relationship between the time of the music and the psychological time it evokes. Such thinking (which I am not sure I agree with) led me to the idea of the opening of the Cello Sonata of 1948, in which the piano, so to speak, presents "chronometric" time, while the cello simultaneously plays in "chrono-ametric" time. (Carter [1976] 1997, 266)

9 I would have preferred the term ametric music here, had it not already been used as part of Souvtchinsky's expression chrono-ametric music. Common sense would understand ametric as "without (audible) metre," but this is obviously not what Souvtchinsky means. His misnomer is comparable to that of the term atonal music, about which both Schoenberg and Stravinsky complained (Schoenberg [1922] 1978, 432-3; Stravinsky 1942, 38).

10 Upon first hearing, a listener will not know whether, and if so to what point, the passage will be repeated. In this way, the repeat adds an element of surprise, which heightens the tension. 


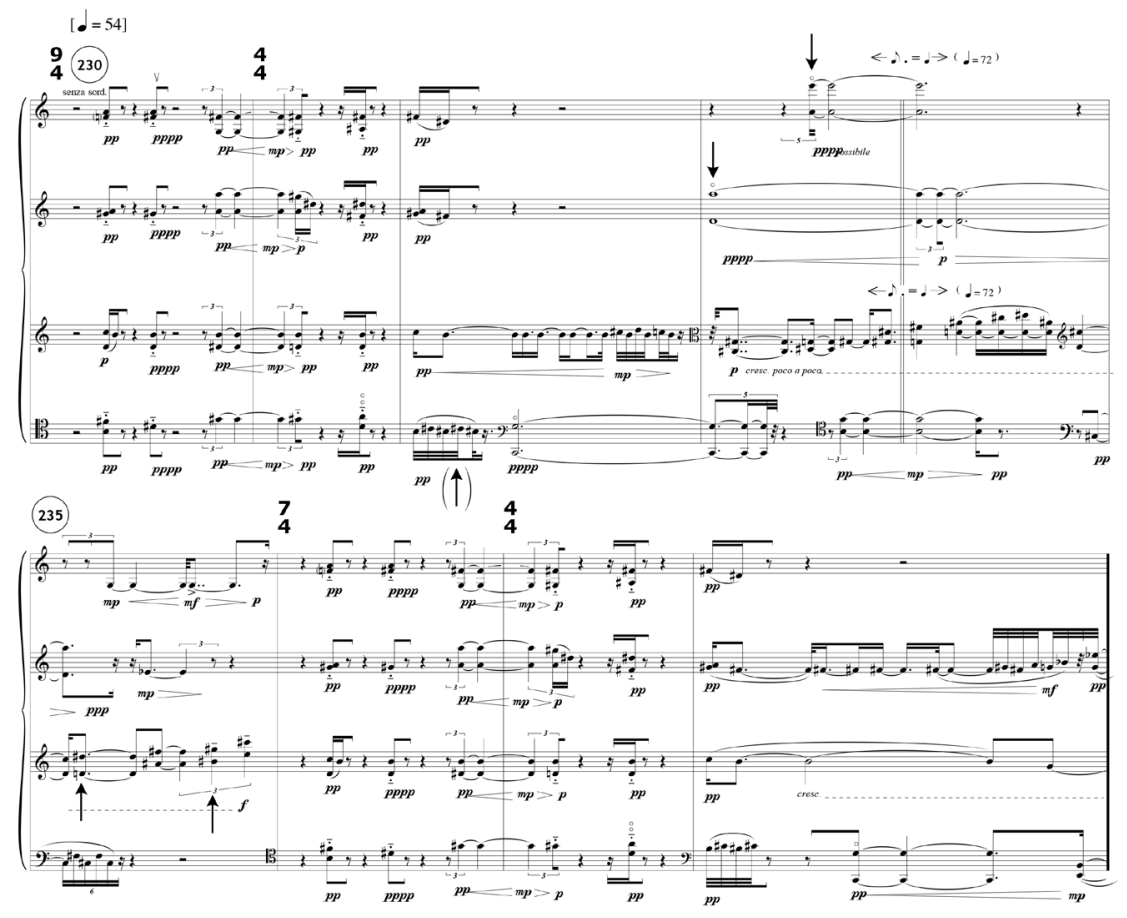

Figure 7. Bars 230-8, vertical arrows added. Bars 233-4 feature metric modulation from $\downarrow=54$ to $\bullet=72$.

grouping structure we probably lack a sense of tempo here and with the many rests are left with only a fuzzy grasp of ontological time. Time seems to stand still. Against everything that came before, bars 230-1 and bars 236-7 stand out in their "timelessness" yet strongly bond with the surrounding music.

While at the foreground level ontological time is experienced in a variety of ways, depending on the particular musical fabric, as we have seen, on a more abstract level ontological time unfolds evenly in this quartet, not only in the trivial sense of the passing of real or clock time, but also in the way Cherney articulates it through a regular polyrhythmic grid in the background. This polyrhythm, which in the preface to the score he refers to as "breathing rhythms," runs through the entire work, variously foregrounded or hidden but unaffected by the actual metronomic tempi. In a few places we hear these "breathing rhythms" in isolation, such as at the beginning of figure 3 above, where we observed the layering of repeating duration patterns. Figure 8 extracts these rhythms from Cherney's draft for the large-scale rhythmic patterning of the work. ${ }^{11}$ They are actually the first four of seven layers that make

11 This draft consists of the overview diagram shown in figure 14 below followed by thirty-four pages of graph paper on which Cherney works out the "breathing rhythms" for the entire work as well as certain score passages. The remaining sketches are found on thirty-six pages of ten-stave music paper in a spiral-bound sketchbook and two separate pages of twenty-two-stave music paper. 


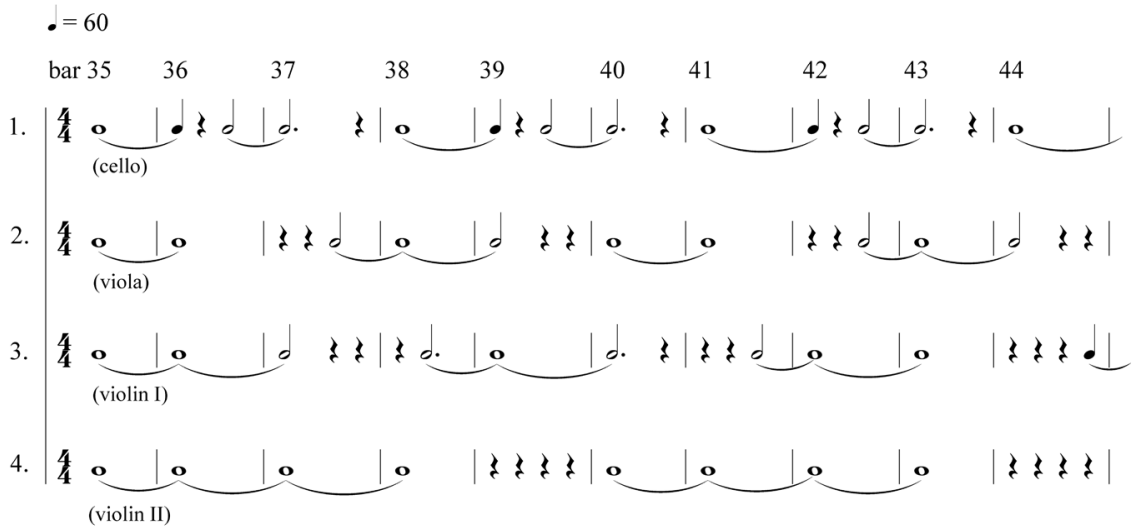

Figure 8. "Breathing rhythms" for bars $35-44$, information taken from sketch

up the "breathing rhythms." As explained in figure 9, measured in clock time the pattern in the first layer repeats every six seconds (divided into five seconds of sound and one second of rest), that of the second layer every ten seconds (divided into eight seconds of sound and two seconds of rest), and so forth. ${ }^{12}$ The onset of all seven layers, whether they actually sound or not, takes place on the downbeat of bar 35 (figure 3), which is probably why Cherney presents the rhythms in isolation here for a few bars. ${ }^{13}$

In his draft Cherney refers to this quiet moment as "Refrain I," because the quartet returns to this kind of texture in a number of places, as we will see. ${ }^{14}$ The polyrhythm continues through the rest of the movement, through various tempo and time signature changes, and after the last bar (bar 417) wraps around to the beginning. The full cycle of the entire seven-layer polyrhythm lasts twenty-six minutes. ${ }^{15}$ It starts in bar 35 and comes to a close, via the wraparound, precisely at the end of bar 34 (not shown here). Most of the time, the "breathing rhythms"-and with them their structuring of ontological timeare not directly audible in the quartet, but hidden. In the score excerpts of figures 1, 3, 5, and 7 above, and in figures 18 and 20 below, I have marked with vertical arrows those moments that correspond to attack points from the underlying "breathing rhythms." Often such moments are approximated, in which case I show the arrow in parentheses, such as at the very beginning of

12 As Brian Cherney explained to me, he calculated the first duration of six seconds as approximately the duration of breathing in and out once in a leisurely breath. The following durations get longer in moderate increments not guided (in the composer's mind) by a particular numerical pattern (beyond the durations of the rests increasing in increments of one). Cherney could not use something like a Fibonacci series because its values increase too sharply.

13 Layers 5-7 are absent altogether in bars $35 \mathrm{ff}$., but their virtual onset also falls on the downbeat of bar 35 .

14 As mentioned in note 31 below, Cherney later also uses the term Refrain for another material, that in bars $230-1$ and $236-7$.

15 The product of the prime factors of the seven different durations shown in figure 9, measured in seconds (i.e., at tempo $=60$ ), is $2 \times 2 \times 2 \times 3 \times 5 \times 13=1,560.1,560$ seconds $/ 60=26$ minutes. Performers are likely to play the quartet in a slightly slower tempo, which results in a duration of about half an hour. 


\begin{tabular}{|c|c|c|}
\hline 1. $5 .+?$ & $=6$. & $(=6 ")$ \\
\hline $2.8 \cdot+3 ?$ & $=10$ & $(=10 ")$ \\
\hline 3. 10. + 39 & $=13$. & $\left(=13^{\prime \prime}\right)$ \\
\hline 4. $16 .+39 ?$ & $=20$. & $(=20 ”)$ \\
\hline $5.19 \cdot+39 ? 3 ?$ & $=24$. & $(=24 ")$ \\
\hline 6. 20. +39393 & $=26$ & $\left(=26^{\prime \prime}\right)$ \\
\hline 7. 23. + $39 x+3 y z$ & $=30$. & $(=30 ”)$ \\
\hline
\end{tabular}

Figure 9. Durations for "breathing rhythms" at tempo $\bullet=60$

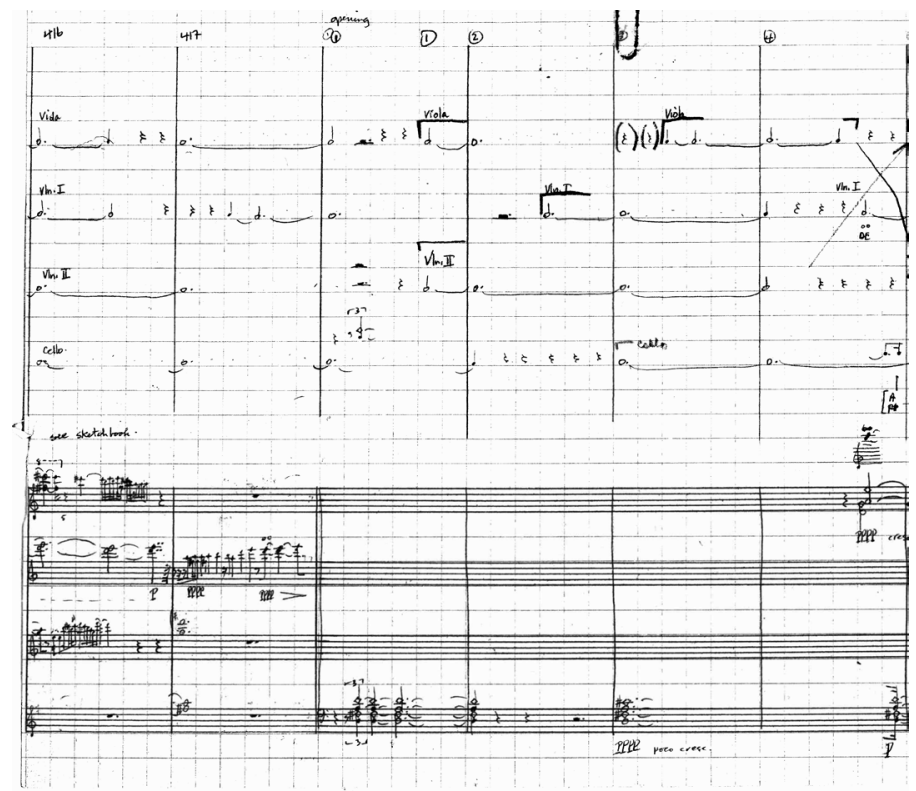

Figure 10. "Breathing rhythms" (top) and partial draft (bottom) for bars 416-17 and 1-4, excerpt from sketch

the work. Figure 10 reproduces an excerpt from Cherney's draft that shows at the top the four layers of the polyrhythm that are active here (layers 2-5, compare with figure 9), linking the last two bars (bars 416-17) with the beginning of the work (bars 1-4). In the final scoring (figure 1) the cello enters in bar 1 softly in the midst of a duration, as if the music had already been ongoing, which conceptually, via the wraparound shown in figure 10, it in fact has. In figure 1 the second violin and viola come in slightly after the point of entry mandated by the polyrhythm given at the top of figure 10. On the other hand, the following entries in figure 1 in the first violin (bar 2), cello and viola (bar 3), and again first violin (bar 4) occur exactly as prescribed by the polyrhythm in figure 10.

Figure 11 shows the "breathing rhythms" for bars $81-8$ from the draft. Since the absolute durations (in clock time) in each layer remain unaltered throughout the quartet, independent of the actual metronomic tempo, the note values are prorated here to the new tempo of $\downarrow=108$ with rests eliminated by being 


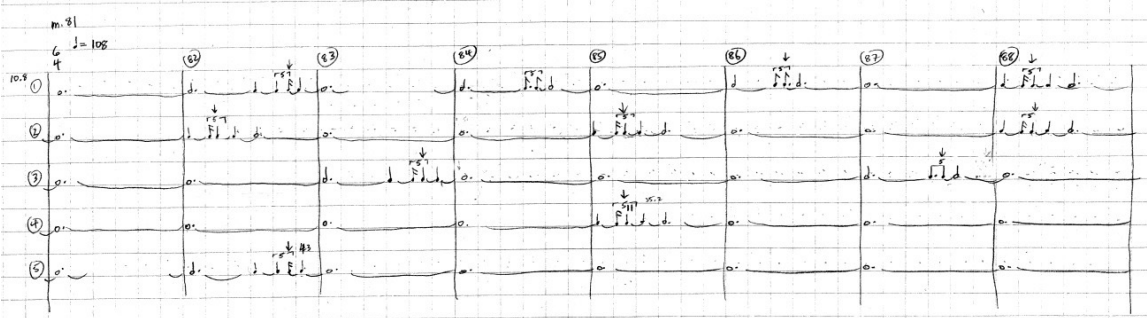

Figure 11. "Breathing rhythms" for bars 81-8, excerpt from sketch

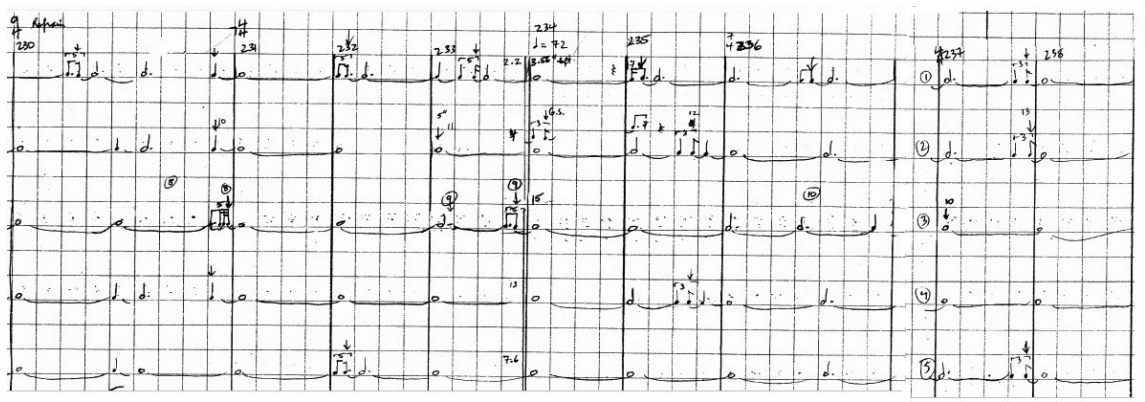

Figure 12. "Breathing rhythms" for bars 230-8, excerpt from sketch

absorbed into these durations. ${ }^{16}$ Not all attacks of the "breathing rhythms" are actually realized in the final score-compare figure 11 with figure 5, bars $81-8$ - nor are the featured attacks somehow differentiated by colour, dynamics, or articulation from the rest of the texture. We basically do not hear the "breathing rhythms" as such here; their presence is relegated entirely to the background level. This is also true for figure 7 above, the "breathing rhythms" for which, as Cherney drafted them, are shown in figure 12. Only a few attack points from these rhythms coincide with events in the final score, those marked with vertical arrows in figure 7. Most notably, the "breathing rhythms" have no presence at all in bars 230-1 and 236-7, where, as observed earlier, time seems to stand still.

Over the grid of the "breathing rhythms," which configure the total length of the work, Cherney superimposes a number of further formal structures, as he explains in his score preface, the second half of which is excerpted below. My diagram in figure 13 summarizes this information and illustrates the overall form of the quartet, drawing also on information from Cherney's overview

16 The adjusted note values for the "breathing rhythms" in tempo $\bullet=108$, maintaining the same durations in clock time, are:
1. $54 \cdot 5(=6 ”)$
2. $18 \cdot\left(=10^{\prime \prime}\right)$
$3.117 \cdot 5(=13 ")$
4. 36 • (=20")
5. $216.55(=24 ")$
6. $234 \cdot 55(=26$ ")
$7.54 \cdot(=30$ ") 
diagram reproduced from his sketches in figure 14. In his preface to the score, he writes,

The overall form of the work is provided by three main structures which are superimposed on each other. On one level, the work consists of four main sections which correspond to a traditional four-movement symphonic form: an opening expository section, a scherzo, a slow movement and a finale, all framed by an introduction and coda. On another level, there are, between the introduction and coda, seven sections, the lengths of which are in the same proportion to each other as a smaller-level set of seven durations (ranging from 6 to 30 seconds) which I call "breathing rhythms" and which complete four cycles of $61 / 2$ minutes each over the course of the Quartet (thus the total duration of 26 minutes). The remaining structural element consists of a kind of cadenza for each instrument strategically positioned over the main body of the work, in the order Violin II $\rightarrow$ Viola $\rightarrow$ Cello $\rightarrow$ Violin I. Violin I's cadenza (which occurs just before the coda) is a "double" or variant of Violin II's cadenza (which appears just after the introduction, near the beginning of the main body of the Quartet), thus providing a certain symmetry to the main body of the work. This tends to counteract the asymmetrical nature of certain other formal structures. ${ }^{17}$

With a full score and figures 13-14 at hand, the interested reader can easily locate the different sections in this multilayered form of the quartet. While some formal markers are readily recognizable in the score and to the listener, such as the beginning of the "main body of the work" and the beginning of the coda (not shown here), which both set out with the kind of refrain we saw in figure 3 , other structural moments are more oblique. ${ }^{18}$ Breaking the symmetrical lengths of the "four cycles of $6 \frac{1}{2}$ minutes each" (illustrated at the top of figure 13), cycles I through III taken together are subdivided asymmetrically into seven sections whose lengths replicate the proportions that govern the "breathing rhythms." 19 I have shown these proportions in figure 13 under "Proportions (of sections)" by way of the seven values from figure $9(6,10,13$, etc. in the order

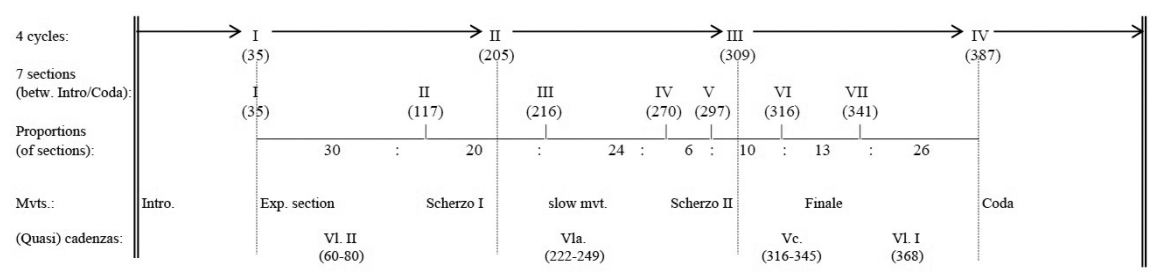

Figure 13. Large-scale form summarized

17 Cherney (1994).

18 Note in figure 14 Cherney's specific mention of "Refrain" at the beginning of section I, in the coda (at this point still with a question mark), and in a few other places.

19 As shown earlier (note 15), the complete cycle of the "breathing rhythms" takes twenty-six minutes. The "four cycles of $61 / 2$ minutes each" that Cherney mentions, each lasting only a quarter of this full duration ( 26 minutes $/ 4=61 / 2$ minutes), each corresponds to a full cycle involving layers $1,2,3$, 


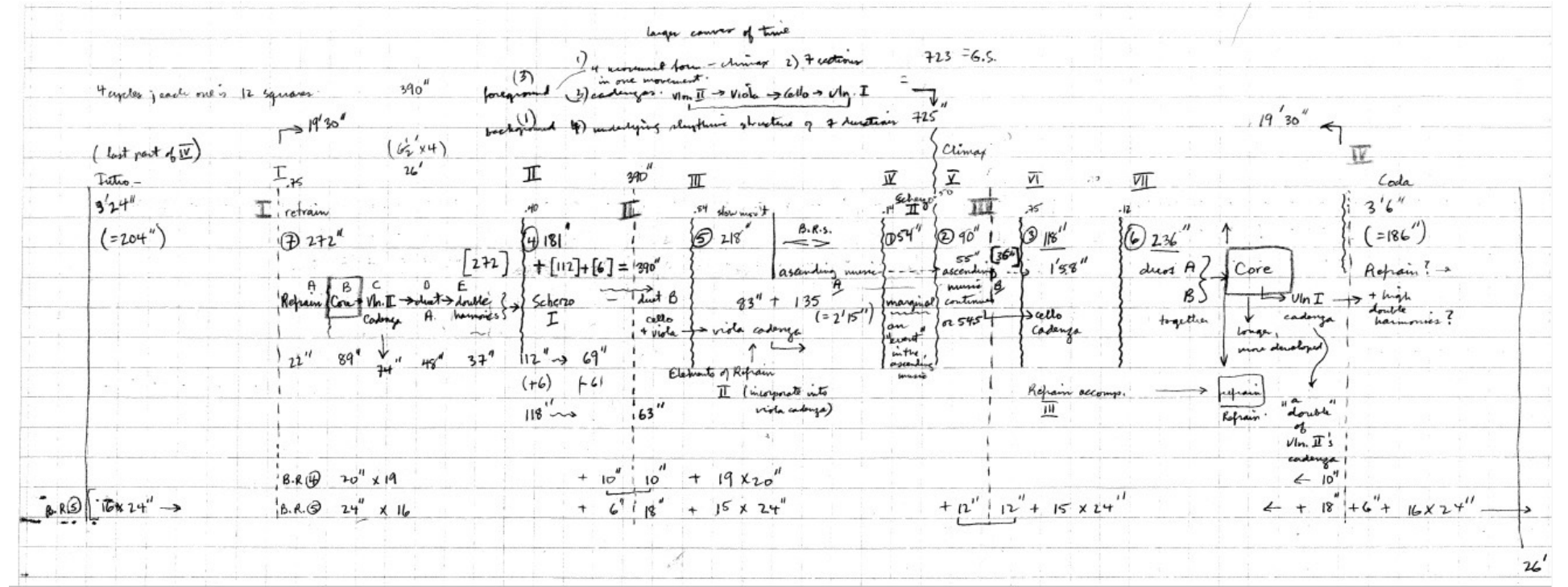

Figure 14. Cherney's overview diagram for the form of the quartet, excerpt from sketch 
$30,20,24,6,10,13,26) .{ }^{20}$ The multi-movement "symphonic form" that Cherney mentions aligns with certain of these seven sections: the "expository section" coincides with section I, Scherzo I with section II, and so forth. Divisions into seven sections or movements are common in Cherney's music. ${ }^{21}$ In this quartet the symbolism of the number seven additionally extends into the seven layers of the "breathing rhythms." The temporal proportions (6:10:13:20:24:26:30) are asymmetrical, but the seven-layer polyrhythm generated from them creates symmetry on a larger scale. ${ }^{22}$

Cherney's Fourth String Quartet shares aspects of its clockwork and form with a preceding work, Die klingende Zeit for chamber ensemble of seven (!) performers, composed less than a year earlier. ${ }^{23}$ This work uses the same "breathing rhythms" (with the same durations and proportions) but realizes only three of the four $6 \frac{1}{2}$-minute cycles, which here symbolize in compressed form three of the four quarters of the day (first quarter from noon to 18:00, second quarter from 18:00 to midnight, third quarter from midnight to 6:00). The fourth quarter (from 6:00 to noon) exists, symbolically, "only in the imagination" (Cherney 2002). Cherney explains that in Die klingende Zeit, as evoked by its title, the passing of time is made audible literally:

At the appropriate places during these three sections ... the "canonical hours" are "chimed," using various instrumental resources ... and at certain places, the current "time" in the twenty-four-hour cycle (proportioned in scale to the four cycles of the chronological time of the piece) is rung in the manner of a "minute repeater" watch ... . Thus, on one level, the piece is about time made "audible" but on another level it is about the way we experience music during the passage of chronological time. The "chiming" of "time(s)" during the piece is thus intended to be a symbol of a deeper preoccupation with the experiential time of music. ${ }^{24}$

6 , and 7 only of the "breathing rhythms" (product of prime factors $2 \times 3 \times 5 \times 13$, measured in seconds, rather than the full $2 \times 2 \times 2 \times 3 \times 5 \times 13$ ).

20 Brian Cherney conveyed to me that he likes to nest durations in an irregular way such as in the ordering chosen here.

21 As he explained to me, he employs the number seven for its cabbalistic, mystical properties and for its practicality as a "symmetrical" (i.e., uneven) number and a kind of Goldilocks value (i.e., for its being not too large and not too small).

22 Suffice it to point out two more details in the score excerpts we have seen earlier with respect to the diagrams of figures 13 and 14: bars 79-80 in figure 5 feature the end of the second violin's cadenza, which in bar 80 prepares the metric modulation. Figure 7 (bars 230-8) is part of the "slow movement" with the viola cadenza in progress. It is again the instrument with the cadenza that highlights the metric modulation here, in bars 233-4. The idea of assigning a cadenza to each of the four instruments is influenced by the Second String Quartet of Elliott Carter, which features three cadenzas between movements (cadenza for viola between movements I and II, cadenza for cello between movements II and III, and cadenza for the first violin between movements III and IV). I wish to thank John Rea for pointing this out to me (with confirmation from Brian Cherney).

23 According to the preface to the score, Die klingende Zeit was written between October 1993 and the beginning of February 1994 (Cherney 2002). String Quartet no. 4, according to its preface, was composed in the fall of 1994 and completed on 28 December of that year.

24 Cherney (2002). 


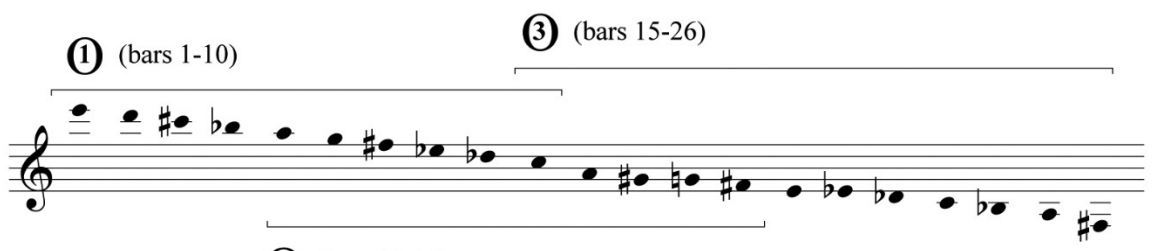

(2) (bars 11-14)

Figure 15a. Pitch mode used in bars 1-34 and many other parts of the quartet

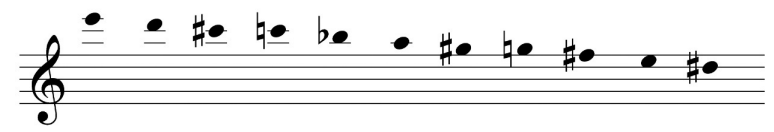

Figure 15b. Expansion of pitch material in the upper octave of the mode. Information taken from sketch.

With respect to the experience of time, much the same can be said of the Fourth String Quartet, except that the passing of chronological time is articulated in the quartet in more concealed ways, without "chiming" clock time. Pitch organization plays a central role in the experience of time as well, and I would like to conclude this analysis with an outline of the principles of Cherney's pitch structures and their temporal unfolding in the work.

Much of the quartet is organized along prolonged pitch fields. This creates a sense of steadiness and-to a certain extent already upon first hearingfamiliarity, because stable pitch grids provide listeners with something to hold onto while they follow the development on the musical surface (which itself is not predictable). In this way, the music often feels "stretched out" in time, imparting a strong sense of continuity. The Introduction of bars 1-34, the beginning of which we saw in figure 1, for instance, is built almost entirely from the pitch gamut shown in figure 15a. As documented in the sketches, this fixed mode, whose pitch-class sequence repeats only partially at the octave, is developed from the overtones of what Cherney calls an "A-chord as basic reference harmony," shown in figure 16. The mode (figure 15a) lacks pitch classes $\mathrm{F}$ and $B$ altogether and does not incorporate the $G \sharp 5$ from the overtone collection in figure 16. However, an extended version of the upper octave of the mode shown in figure 15b, transcribed from the sketches for a later passage (around bar 120), does incorporate this $G_{\sharp 5}$ (but still omits pitch classes F and B). This mode and its variants recur throughout the work. ${ }^{25}$

The "opening filigree textures" (Cherney's term in the sketches) in figure 1 move through the mode on wavy paths, as we have seen, first covering the high register (bracket \#1 in figure 15a marks the region used in bars 1-10) and gradually proceeding into lower ranges (those bracketed \#2 and \#3 for bars

25 Brian Cherney explained to me that the collection in figure 16 comes from what he calls the "great attractor chord," a twelve-note chord he used in Et j'entends la nuit qui chante dans les cloches (1990) for piano and orchestra. The chord consists of pitches $\mathrm{C}_{4}, \mathrm{E}_{4}, \mathrm{G}_{4}, \mathrm{~A}_{4}, \mathrm{C}_{5}, \mathrm{E}_{5}^{b_{5}}, \mathrm{~F}_{5}, \mathrm{G}_{5}, \mathrm{~B}_{5}, \mathrm{D} 6$, $\mathrm{F} 6, \mathrm{~B}^{\mathrm{b}} 6$. Cherney calls the bottom pentachord ( $\left.\mathrm{C}_{4} 4, \mathrm{E}_{4}, \mathrm{G}_{4}, \mathrm{~A}_{4}, \mathrm{C}_{5}\right)$ "magic chord" and frequently uses it and similarly spaced pentachords (all octatonic, but of different set types) in his music. 


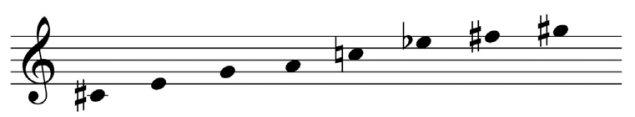

Figure 16. Selected partials from the overtone series on A1 developed into the mode of figure 15a (except for $\mathrm{G}_{55}$ ). Information taken from sketch.

[a]

[b]

[c]

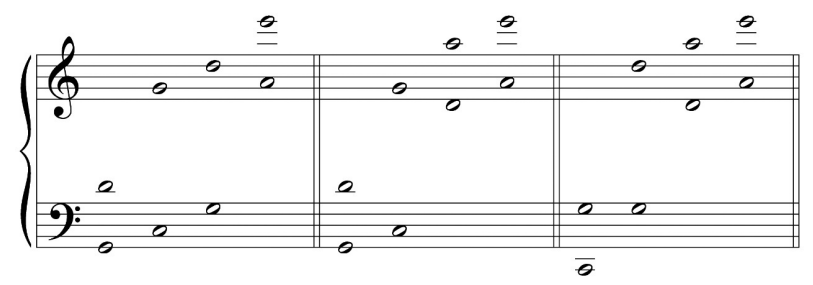

Figure 17. The three sets of twelfths used for the refrain music, information taken from sketch. The refrain in bars $35 \mathrm{ff}$. (figure 3) presents [b], the one in bars $387 \mathrm{ff}$. (not shown) features $[c]$.

11-14 and 15-26 respectively). Pitches foreign to the mode occur occasionally in this material before bar 25, and more frequently afterwards until bar 34 . Furthermore, long sustained open twelfths characteristic of the later Refrain music (figure 3) begin to make their appearance from bar 9 on, adding several pitches not contained in the mode. Figures $17 \mathrm{a}-\mathrm{c}$ show the three different versions of sets of twelfths used for the Refrain music, transcribed from Cherney's sketchbook. Each twelfth consists of an open-string pitch at the bottom and a natural octave-harmonic on the next higher string; the only difference between versions [a] and [b] is the dyad assigned to the second violin. When the Refrain enters the first time in bar 35 (figure 3), prolonging the stacked twelfths from figure $17 \mathrm{~b}$ via the slow polyrhythmic pulsations discussed earlier, the air has been cleared of all prior chromaticism. Chromatically enriched runs return from bar 40 on, expanding the mode from figure 15 a into the lower register of the cello (as had happened in the bars leading up to the refrain, not shown here) and also occasionally adding new pitches in the upper range of the mode. ${ }^{26}$ Obviously it is not only the increased rhythmic activity that makes time seem to pass more quickly from bar 40 on, as graphed in figure 4 , but also the increase in (chromatic) pitch content and the concomitant heightening of harmonic tension.

Figure 18 shows the first of several local climaxes in the long passage of "ascending music" between bars 241 and 324 in the centre of the work. (See in figure 14 Cherney's mention of "ascending music" extending from the middle of section III into section V.) It is a local climax, because after reaching the highest pitches in the first half of bar 270 , the texture reaches down to the lowest register in the second half of the bar with the $\mathrm{C} \sharp 2$ in the cello, after which the

26 The principle behind this pitch expansion is not documented in the sketches, but we can notice that the pitches added in the lower octave of the cello roughly replicate the pitch density prevalent higher up in the mode. 


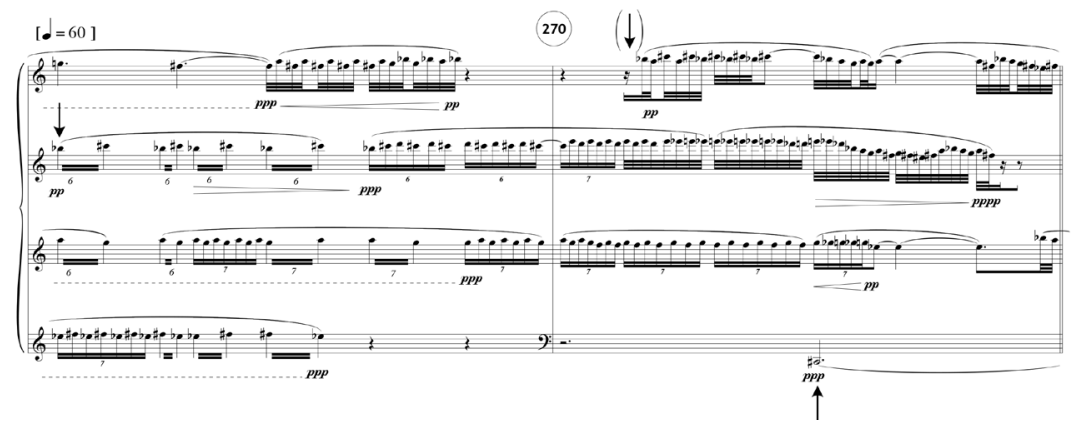

Figure 18. Bars 269-70, vertical arrows added

material in the upper three strings drops (into the following bars, not shown) before the next ascent begins. This is one of those moments I mentioned earlier in my description of the listening experience where to me the music feels as if it is slow and (moderately) fast at the same time. Figure 19 explains why this is so, by parsing out the three temporal strata through which we may experience this passage. The bottom of the figure (at $\gamma$ ) illustrates how slow the harmonic rhythm is, by reducing all oscillations between two (or among three) notes to sustained pitch simultaneities. (The four staves at $\gamma$ do not represent the four string instruments but simply constitute an extended "piano score.") As we easily recognize from this reduction, this slowly moving harmony is derived almost entirely from the mode familiar from figure 15a. (The two pitches that lie outside the mode, $\mathrm{F}_{5}$ and $\mathrm{E}^{b} 6$, are marked with an asterisk at $\gamma$.) The middle of figure 19 (at $\beta$ ) reproduces the oscillating gestures prolonging the harmony. Because of their repetitive nature, their overall effect is mostly static, but given the rhythmic activity, time appears to pass here slightly faster than it would if we were focusing on the harmonic rhythm shown at $\gamma$ alone. Finally, $a$ illustrates those components of the passage that are directional, that is, where the overall effect of a gesture is not static, because it changes location more rapidly. In those moments time appears to go by faster because of the increase in new information we have to process in time, while at the background level ( $\beta$ and $\gamma$ ) time still passes more slowly because of the continuing slow rate of change. This is why here and in similar situations elsewhere in the quartet the music seems to be slow and fast at the same time. ${ }^{27}$

In addition to drawing us into the multifaceted experience of musical time that I have examined here, Brian Cherney's Fourth Quartet invokes the notion of time in another, metaphorical dimension. The work was commissioned by the Penderecki String Quartet to be premiered in "one of three CBC concerts in Montréal commemorating the fiftieth anniversary of the end of World War II" (Cherney 1994). In reference to this, the quartet features modified quotations "of a well-known popular song from the War years" as well as "brief references

27 The effect is comparable to that of a "fast" section in a slow classical sonata movement where runs of thirty-seconds are set against a continuous slow harmonic rhythm, for example. Such passages also feel slow and fast at the same time. 
$\alpha$
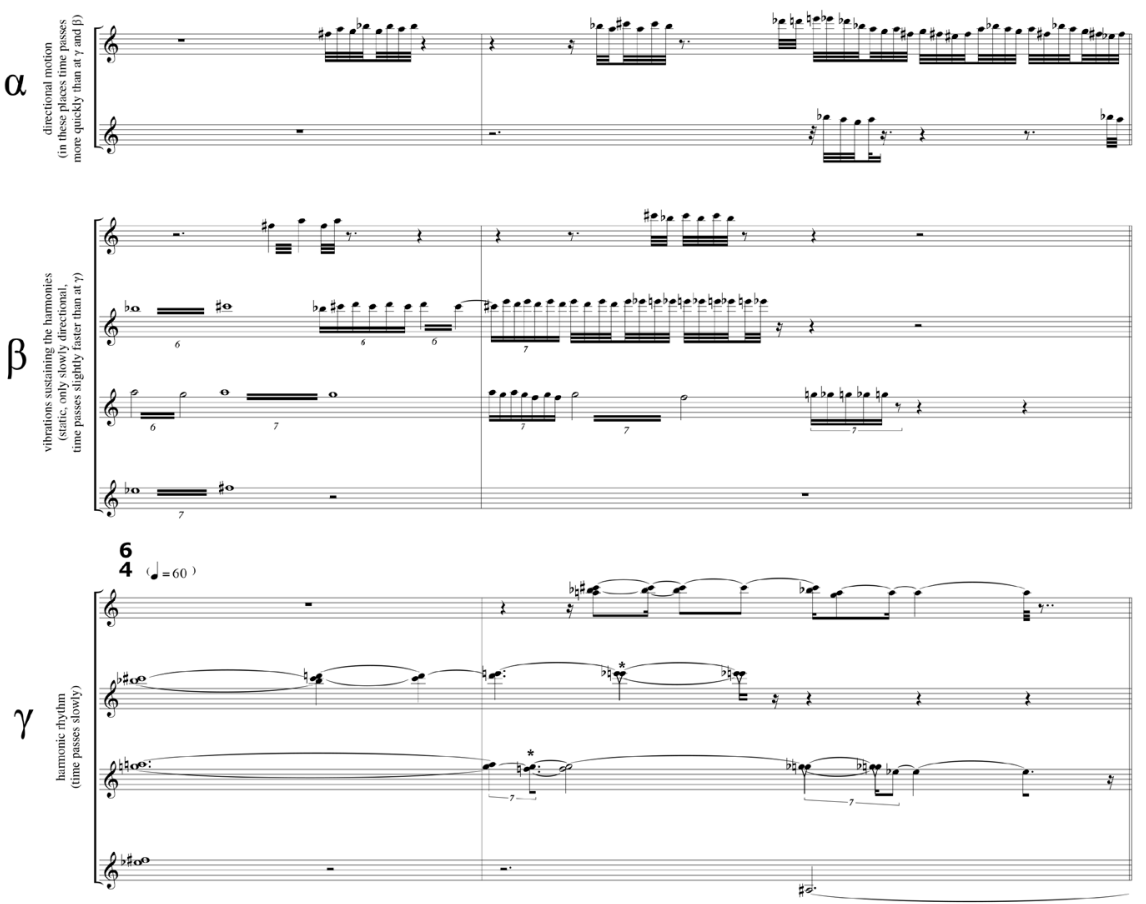

Figure 19. Analysis of three temporal layers in bars 269-70. The two pitches outside the mode from figure $15 \mathrm{a}\left(\mathrm{F}_{5}\right.$ and $\mathrm{E}^{\mathrm{b}} 6$ ) are marked with an asterisk at $\gamma$.

to two works of Béla Bartók," who passed away in exile in New York in 1945 (Cherney 1994). ${ }^{28}$ We saw one Bartók reference in figure 5, in the pizzicato line of the cello in bars 81-3. Its first twelve notes come from the first-violin melody starting at bar 449 (arco and legato) of the fifth movement from Bartók's Concerto for Orchestra (1943), transposed. At the same time, as Brian Cherney pointed out to me, the articulation of this melody as a cello pizzicato line is an allusion to a similar gesture in bars $144-6$ of the first movement from Elliott Carter's First String Quartet. ${ }^{29}$ The viola melody in bars $400-8$ of figure 20

28 I wish to thank Brian Cherney for helping me identify the various quotations and allusions in the quartet. Cherney also uses the number fifty and the sequence of numbers in 1945 and 1995 "to control the duration and certain patterns of repetition during the central part of the work" (Cherney 1994), which I do not examine here.

29 Further allusions to Carter, as Brian Cherney pointed out to me, aside from the cadenzas as reference to Carter's Second String Quartet mentioned earlier, include the viola-cello duo in bars 84-7 of Cherney's quartet (alluding to the duo of the violins in bars 144-55 of the first movement from Carter's First Quartet), the many places in Cherney's quartet that superimpose slow and busy music such as in bars $341-8$ (referring to places like bars 166-74 in the same Carter movement), and allusions to the scherzo textures in the second movement of the same Carter Quartet (for example in bars 121-36 of Cherney's quartet, which are in the same tempo as the opening of Carter's movement). According to Cherney, these allusions as well as other elements influenced by the music of György Ligeti, for instance, such as the staggered dynamic relationships in bars 31-4 (not shown here), serve dramatic purposes. Cherney's quartet also features self-references, such as in a reference in bars $301 \mathrm{ff}$. to the ascending music in Illuminations (1987) for string orchestra. 
from towards the end of the quartet is an allusion to Bartók-Brian Cherney described it to me as "composed to sound like a folk-song-like lullaby"-set against a static, pulsating background harmony built entirely from the mode in figure 15a. From bar 405 on, this harmony gives way to high sustained harmonics, which recall the ones from the beginning of the work (figure 1). Beginning in bar 408 (figure 20) we hear in the second violin a last modified version of the melody from the popular song "Lili Marleen" (music by Norbert Schultze, verses by Hans Leip) made famous during the war, especially by Marlene Dietrich..$^{30}$ As documented in the sketches, the pitches of the sustained harmonics in cello, first violin, and viola are all chosen from the overtone series over D2, replacing the eleventh partial G\#5 with G5, whereas the melody of "Lili Marleen," in D major, is altered in bar 408 (as elsewhere in the quartet) to feature a Lydian $\mathrm{G} \#$ instead of G. Sharing its tonic pitch class D with the fundamental of this overtone series, this melody hovers in a high register where each of its pitches can be heard as a partial of the overtone structure. In the final bars of the quartet following this example (not shown), the melody dissolves into the surrounding field of sustained harmonics, which in turn loop back to the beginning of the work. (Compare the harmonics in the cello in bars 405-7 and 408-11 of figure 20 with those in bars 1-2 and 3-4 respectively of figure 1, for instance.) By this point, time thus seems to be progressing both forward and backward..$^{31}$

The references to the end of the Second World War by allusions to Bartók, "Lili Marleen," and certain numbers associated with the fiftieth anniversary in 1995 open up a temporal space beyond the here-and-now of the quartet. At the premiere, audience members of Brian Cherney's generation would recall the semi-centennial time span since the war as something they had experienced themselves. For younger listeners these references create an imaginary experience of historical time.

30 Modified versions of "Lili Marleen" are quoted earlier in the quartet starting in bars 157 (first violin), 282 (first violin), and 371 (viola). The viola melody in bars $400-8$ alludes to this tune as well through shared rhythms and pitch material.

31 Space does not allow me to go into more detail of Cherney's pitch organization in the work, which can be summed up as moving in and out of the mode in figure 15 (developed from the overtone series on A1 as per figure 16), the diatonically stacked open twelfths in figure 17 , and the static pitch field derived from the overtone series on D2 just mentioned. The passages shown in figures 1, 3 , 18 , and 20 are all based on these materials. Figure 5 abandons the mode by way of motion mostly in parallel minor sixths in bars 80 and $84-7$, and via the chromaticism of the Bartók quote in bars 81-3. Furthest removed from the mode, stacked twelfths, and overtone harmony is the pitch material of the chords in figure 7, bars 230-1 and 236-7 (which in his sketchbook Cherney also refers to as "Refrain"), where time seems to stand still. While the principle behind their construction is not documented in the sketches, we can safely say-given Cherney's predilection for octatonic harmonies-that the first two chords are built from collection $\mathrm{OCT}_{\mathrm{C}, \mathrm{D}}$ (octatonic collection containing $\mathrm{C}$ and $\mathrm{D}$ ), emphasizing densely packed tonal sonorities. The following chords expand the tessitura and pitch-class collection, moving beyond the octatonicism of the previous ones, but maintain a focus on embedded tonal chords. 


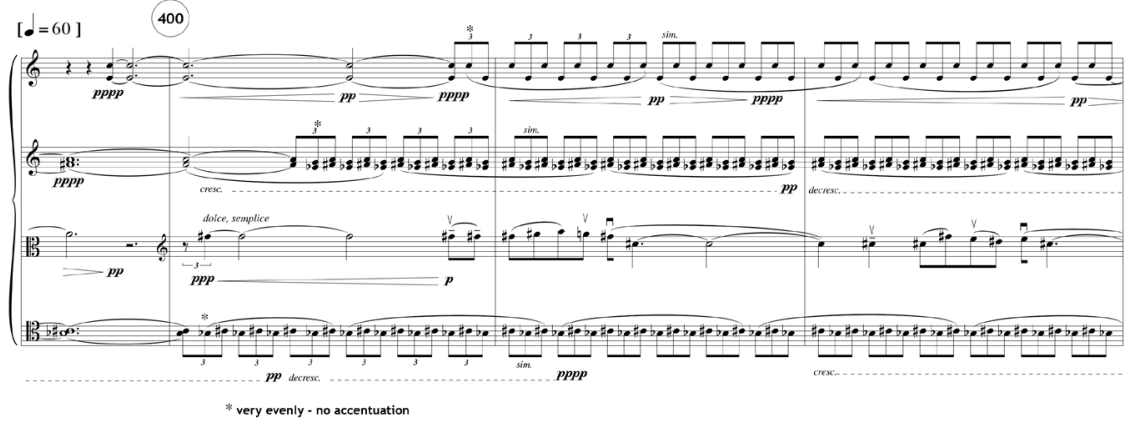

(405)

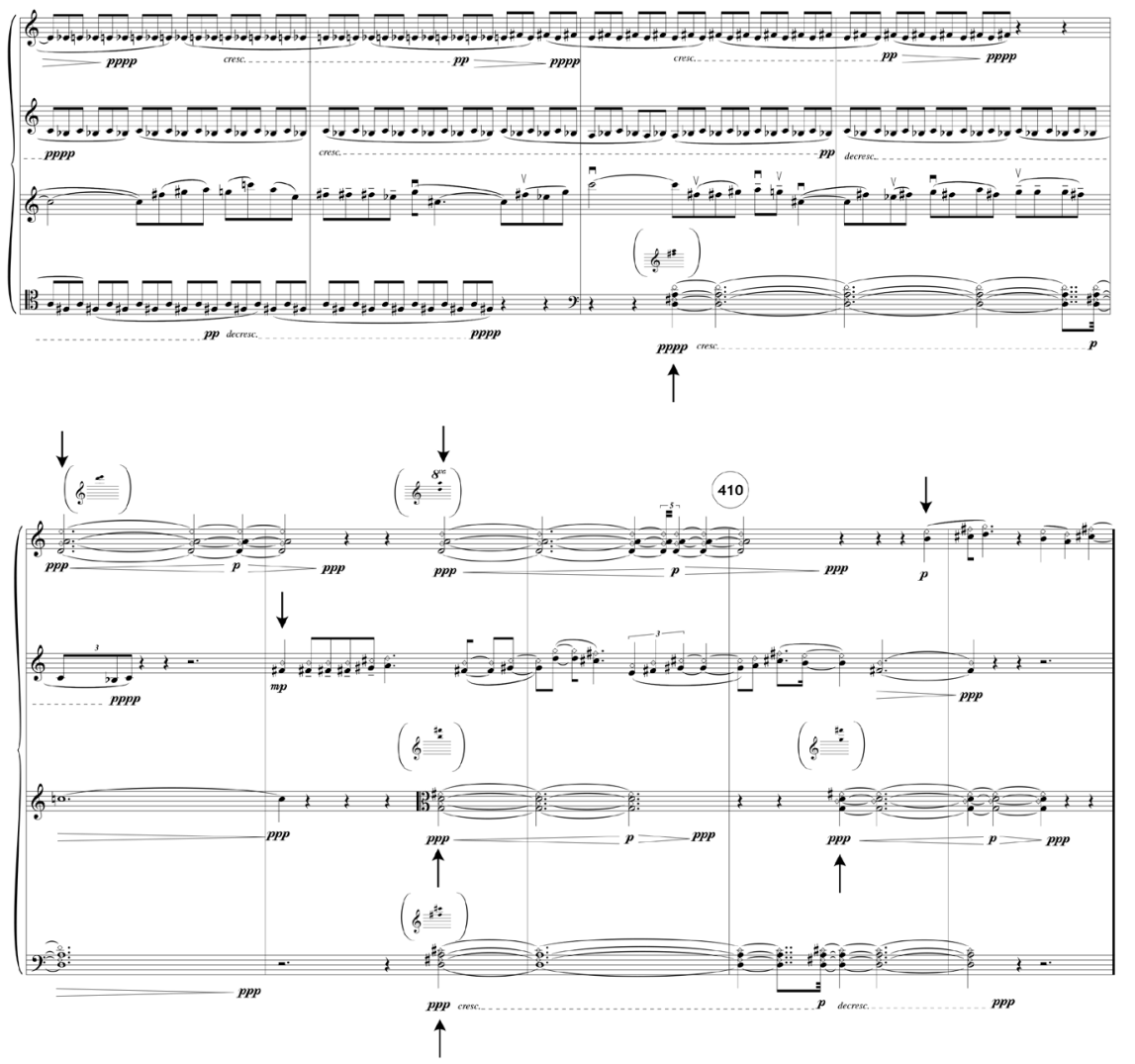

Figure 20. Bars 399-411, arrows added from bar 405 on ("breathing rhythms" do not materialize in the previous bars) 


\section{REFERENCES}

Akimova, Irina. 2011. Pierre Souvtchinsky. Parcours d'un Russe hors frontière. Paris: L'Harmattan.

Brelet, Gisèle. 1949. Le Temps musical: Essai d'une esthétique nouvelle de la musique. 2 vols. Paris: Presses Universitaires de France.

Carter, Elliott. (1965/94) 1997. “Time Lecture." In Collected Essays and Lectures, 1937-1995, edited by Jonathan W. Bernard, 313-18. Rochester: University of Rochester Press.

_. (1976) 1997. “Music and the Time Screen." In Collected Essays and Lectures, 1937-1995, 262-8o. Rochester: University of Rochester Press.

Cherney, Brian. 1994. String Quartet no. 4, ( 1994 Brian Cherney, unpublished score.

- 2002. Preface to Die klingende Zeit (score). Saint-Nicolas, QC: Doberman-Yppan.

Dufour, Valérie. 2004. "Strawinsky vers Souvtchinsky. Thème et variations sur la Poétique musicale." Mitteilungen der Paul Sacher Stiftung 17: 17-23.

Koechlin, Charles. 1926. "Le Temps et la musique." Revue musicale (January): 45-62.

Krenek, Ernst. (1944) 1993. "Musical Time." Newsletter of the Ernst Krenek Archive $3(2-3): 1,11-13$.

Schoenberg, Arnold. (1922) 1978. Theory of Harmony, translated by Roy E. Carter. Berkeley: University of California Press.

Soumagnac, Myriam. 200o. "Préface." In Igor Strawinsky, Poétique musicale sous forme de six leçons, edited by Myriam Soumagnac, 11-55. Paris: Flammarion.

Souvtchinsky, Pierre. 1939. "La notion du temps et la musique (Réflexions sur la typologie de la création musicale)." Revue musicale (May-June): 70-80.

Stockhausen, Karlheinz. (1955) 1988. "Struktur und Erlebniszeit" (Structure and experiential time). In Texte zur elektronischen und instrumentalen Musik, edited by Dieter Schnebel, 1: 86-98. Cologne: DuMont Buchverlag. Stravinsky, Igor. 1942. Poetics of Music in the Form of Six Lessons, translated by Arthur Knodel and Ingolf Dahl. Cambridge, MA: Harvard University Press.

\section{ABSTRACT}

Brian Cherney's Fourth String Quartet (1994), in one movement lasting half an hour, is striking for its formal coherence and diversity of materials. The work achieves large-scale cohesion not only through an intricate interplay of three simultaneously unfolding "main structures"-four attacca movements in one, on one level, seven sections forming certain temporal proportions, on another, and four cycles of "breathing rhythms" derived from the same proportions on a third level, as documented in the manuscript sources-but also through the continually fluctuating tension we experience throughout the movement between ontological and psychological time. Pierre Souvtchinsky's notion of a "counterpoint" between "ontological time" (i.e., clock or real time) and a particular music's inherent time shaped by "the material and technical 
means by which [the] music is expressed" is referenced to demonstrate how in Cherney's quartet fixed proportions and slow, stable polyrhythms active in the background afford space for foreground activity that has its own sense of time. The article further explores the notion of time in a second, metaphorical dimension, as concerns intertextual allusions in the quartet.

\section{RÉSUMÉ}

Dans un mouvement d'une durée d'une demi-heure, le Fourth String Quartet (1994) de Brian Cherney est frappant par sa cohérence formelle et la diversité du matériel. L'œuvre atteint une vaste cohésion non seulement par le jeu complexe de trois «structures principales» qui se manifestent simultanément-quatre mouvements attacca en un, à un niveau, sept sections formant certaines proportions temporelles à un autre, et quatre cycles de «rythmes de respiration» dérivés des mêmes proportions à un troisième niveau, comme le révèlent les sources du manuscrit-mais aussi par la tension fluctuant continuellement que nous sentons dans tout le mouvement entre le temps ontologique et le temps psychologique. L'auteur fait appel à la notion de Pierre Souvtchinsky de «contrepoint» entre le «temps ontologique» (c.-à-d. le temps réel, celui de l'horloge) et le temps propre à une œuvre musicale, façonné par les «moyens matériels et techniques» employés pour exprimer la musique pour montrer comment, dans le quatuor de Cherney, les proportions fixes et les polyrythmes lents et stables à l'arrièreplan créent un espace où peut se dérouler l'activité à l'avant-plan qui a son propre sens du temps. L’auteur explore aussi la notion de temps dans une dimension métaphorique secondaire touchant diverses allusions intertextuelles dans le quatuor.

\section{BIOGRAPHY}

Christoph Neidhöfer is an associate professor at McGill University, Schulich School of Music, where he has been teaching since 1999. He holds diplomas in composition, music theory, and piano performance from the Musikhochschule Basel, and a PhD in music theory from Harvard University. His research focuses on twentieth- and twenty-first-century music, post-tonal theory, sketch studies, aesthetics of serialism, and eighteenth-century counterpoint. 